\title{
Fatty acid profile of plasma and liver lipids in mice depleted in long-chain polyunsaturated (n-3) fatty acids
}

\author{
SEBASTIEN PELTIER ${ }^{1}$, LAURENCE PORTOIS ${ }^{1}$, WILLY J. MALAISSE ${ }^{2}$ and YVON A. CARPENTIER $^{1}$ \\ Laboratories of Experimental ${ }^{1}$ Surgery and ${ }^{2}$ Hormonology, Brussels Free University, B-1070 Brussels, Belgium
}

Received May 27, 2008; Accepted July 3, 2008

DOI: 10.3892/ijmm_00000056

\begin{abstract}
Considering the numerous features of the metabolic syndrome found in rats depleted in long-chain polyunsaturated (n-3) fatty acids and in the perspective of further work conducted in (n-3)-depleted mice, the fatty acid profile of plasma and liver lipids was assessed in both male and female control and second-generation (n-3)-depleted mice. In addition to gender differences, the major alteration found in the (n-3)depleted animals consisted in the expected severe depletion of plasma triacylglycerols and phospholipids, as well as liver phospholipids, in C20:5(n-3), C22:5(n-3) and C22:6(n-3). In plasma triacylglycerols, the weight percentages of C18:2(n-6) and $\mathrm{C} 18: 3(\mathrm{n}-6)$ were lower in (n-3)-depleted mice than in control animals. In both plasma and liver phospholipids, however, the weight percentages of long-chain polyunsaturated (n-6) fatty acids (C20:4(n-6) and C22:4(n-6)) were higher in (n-3)-depleted mice than in control animals. The C16:1(n-7)/ C16:0 and C18:1(n-9)/C18:0 ratio in both plasma and liver phospholipids were also increased in female (n-3)-depleted mice but not so in male animals. Highly significant correlations were found between the weight percentage of each fatty acid in liver versus plasma phospholipids. Taken as a whole, these findings indicate that second-generation mice depleted in (n-3) fatty acids represent a suitable model, in terms of the remodelling of the fatty acid profile in plasma and liver lipids, to investigate the metabolic and functional consequences of such a depletion.
\end{abstract}

\section{Introduction}

Second-generation rats depleted in long-chain polyunsaturated (n-3) fatty acids present several features of the metabolic syndrome including obesity, liver steatosis, insulin resistance and arterial hypertension with cardiac hypertrophy (1-4). Further work is now in progress in second generation (n-3)depleted mice. The present study aimed, therefore, at assessing

Correspondence to: Professor W.J. Malaisse, Laboratory of Experimental Hormonology, Brussels Free University, 808 Route de Lennik, B-1070 Brussels, Belgium

E-mail: malaisse@ulb.ac.be

Key words: (n-3) fatty acids, plasma lipids, liver lipids whether, in the latter animals, the fatty acid profile of plasma and liver lipids display perturbations comparable to those previously documented in second-generation (n-3)-depleted rats.

\section{Materials and methods}

Male and female control mice were obtained from Iffa Credo (L'Arbresle, France). Male and female second-generation (n-3)-depleted mice were kindly provided by UMR 1019, INRA (Université d'Auvergne, Clermont-Ferrand, France). The procedure followed to prepared the latter mice and the diets given to either the control or (n-3)-depleted animals were identical to those described elsewhere (2). The animals were housed in an animal quarter with control temperature $\left(24^{\circ} \mathrm{C}\right)$, hygrometry $(60 \%)$ and brightness/darkness cycle $(12 / 12 \mathrm{~h})$.

Fed animals were sacrificed by $\mathrm{CO}_{2}$ inhalation. The blood collected by heart puncture and a liver sample were handled, as reported previously (1), for measurement of the fatty acid content and profile of plasma and hepatic lipids.

Each individual result refers to pooled samples from either 3 (plasma) or 2 (liver) mice of same sex and same nutritional status [control of (n-3)-depleted rats]. The 3 mice used for each plasma determinations included the same 2 mice used for each liver determination.

Whenever so required, results are presented as mean values $( \pm$ individual variations from such a mean value when derived from 2 measurements, or \pm SEM when referring to more animals), together with the number of individual determinations ( $n$ ). The statistical significance of differences between mean values was assessed by use of Student's t-test.

The present study was carried out in accordance with the principles of the Animal Experimentation Ethics Committee of Brussels Free University Medical School (Belgium).

\section{Results}

Plasma triacylglycerols. Two major sets of differences in the fatty acid pattern of plasma triacylglycerols were observed in the four types of mice (Table I). The first consisted in gender difference. Whether in control or (n-3)-depleted mice, the weight percentages of $\mathrm{C} 18: 0$ and $\mathrm{C} 18: 1(\mathrm{n}-9)$ were indeed higher in female than male animals, the values recorded in the former animals averaging $130.8 \pm 8.2 \%(n=4 ; p<0.02)$ of the corresponding values found in the latter ones. Inversely, 
Table I. Fatty acid pattern of plasma triacylglycerols.

\begin{tabular}{|c|c|c|c|c|}
\hline Rats & M-control & F-control & $M-(n-3) D$ & F-(n-3)D \\
\hline $\mathrm{C} 14: 0(\%)$ & 0.5 & 0.5 & 0.9 & 0.9 \\
\hline C16:0 (\%) & 18.6 & 21.5 & 24.3 & 19.7 \\
\hline $\mathrm{C} 16: 1(\mathrm{n}-7)(\%)$ & 2.6 & 2.1 & 3.7 & 3.7 \\
\hline C18:0 (\%) & 1.4 & 2.2 & 2.4 & 3.0 \\
\hline C18:1(n-9) (\%) & 19.8 & 23.5 & 29.2 & 36.7 \\
\hline C18:2(n-6) (\%) & 37.1 & 38.0 & 31.7 & 31.0 \\
\hline C18:3(n-6) (\%) & 0.6 & 0.6 & 0.5 & 0.0 \\
\hline $\mathrm{C} 20: 0(\%)$ & 0.1 & 0.1 & 0.3 & 0.1 \\
\hline C20:1(n-9) (\%) & 0.7 & 0.9 & 1.1 & 0.9 \\
\hline $\mathrm{C} 22: 0(\%)$ & 1.6 & 2.2 & 4.2 & 3.1 \\
\hline C20:5(n-3) (\%) & 2.4 & 1.5 & 0.0 & 0.0 \\
\hline C22:4(n-6) (\%) & 0.0 & 0.3 & 0.7 & 0.0 \\
\hline C22:5(n-3) (\%) & 1.2 & 0.8 & 0.0 & 0.0 \\
\hline$C 22: 6(n-3)(\%)$ & 12.6 & 5.0 & 0.0 & 0.0 \\
\hline C16:1(n-7)/C16:0 (x103) & 141.0 & 96.5 & 151.1 & 186.2 \\
\hline C18:1(n-9)/C18:0 & 13.87 & 10.67 & 12.44 & 12.34 \\
\hline C20:0/C18:0 (x10³) & 102.0 & 45.3 & 146.1 & 28.9 \\
\hline C20:1(n-9)/C18:1(n-9) (x10 & 37.8 & 37.3 & 38.3 & 25.1 \\
\hline
\end{tabular}

the C20:0 weight percentage and C20:0/C18:0 ratio in plasma triacylglycerols represented in female mice no more than $35.0 \pm 10.0 \%(n=4 ; p<0.025)$ of the corresponding values found in male rats in the same nutritional state [control or (n-3)depleted animals]. In the control animals, the C20:5(n-3), $\mathrm{C} 22: 5(\mathrm{n}-3)$ and $\mathrm{C} 22: 6(\mathrm{n}-3)$ weight percentages in plasma triacylglycerols were also lower in female mice than in male animals, averaging, in the former mice, only $54.9 \pm 9.0 \% \quad(n=3$; $\mathrm{p}<0.02$ ) of the corresponding values found in male animals.

The second set of differences concerned the comparison between control and (n-3)-depleted animals. Thus, whilst control animals displayed sizeable amounts of long-chain polyunsaturated (n-3) fatty acids [C20:5(n-3), C22:5(n-3) and C22:6(n-3)] in plasma triacylglycerols, such was not the case in the (n-3)-depleted mice. Moreover, the weight percentages of C18:2(n-6) and C18:3(n-6) were also lower in (n-3)-depleted mice than in control animals. Even if ignoring the fact that no $\mathrm{C} 18: 3(\mathrm{n}-6)$ could be detected in the triacylglycerols of female (n-3)-depleted mice, the weight percentage of $\mathrm{C} 18: 2(\mathrm{n}-6)$ and $\mathrm{C} 18: 3(\mathrm{n}-6)$ in the (n-3)-depleted animals indeed averaged $85.3 \pm 2.2 \%(n=3 ; p<0.025)$ of the corresponding values found in control animals. Inversely, the weight percentages of C14:0, C16:1(n-7), C18:0, C18:1(n-9), C20:1(n-9) and C22:0 were invariably higher in (n-3)-depleted mice than in control animals of the same sex. In the male and female animals, respectively, the values found in the (n-3)depleted rats averaged $171.4 \pm 16.0 \%(n=6 ; p<0.005)$ and $146.8 \pm 12.0 \%(n=6 ; p<0.01)$ of those recorded in the control mice of same sex. The latter two mean percentages failed to differ significantly from one another $(p>0.2)$, whether by group or paired comparison. No significant difference between control and (n-3)-depleted mice was observed, however, as far as the $\mathrm{C} 16: 1(\mathrm{n}-7) / \mathrm{C} 16: 0$ and $\mathrm{C} 18: 1(\mathrm{n}-9) / \mathrm{C} 18: 0$ ratio $(p>0.3)$ and $C 20: 1(n-9) / C 18: 1(n-9)$ ratio $(p>0.5)$ in plasma triacylglycerols are concerned.

Plasma phospholipids. Gender differences in the fatty acid pattern of plasma phospholipids were not uncommon. For instance, the weight percentage of C20:0, C22:0 and C24:0 averaged in the female mice $72.3 \pm 5.0 \%(n=6 ; p<0.005)$ of the corresponding values found in male mice in the same nutritional status. Likewise, the $\mathrm{C} 20: 0 / \mathrm{C} 18: 0$ ratio only represented, in the female mice, $53.2 \pm 8.1 \%(n=2 ; p<0.06)$ of the corresponding values found in male mice examined in the same nutritional status [control or (n-3)-depleted animals].

Major differences in the fatty acid pattern of plasma phospholipids also concerned the comparison between control and (n-3)-depleted mice (Table II). First, the weight percentage of long-chain polyunsaturated (n-3) fatty acids was much lower in the latter mice than in the control animals. The content of plasma phospholipids in C20:5(n-3) was below the limit of detection in (n-3)-depleted rats, whilst averaging $9.05 \pm 0.34 \mu \mathrm{g} / \mathrm{ml}$ in the control animals. Likewise, in the (n-3)-depleted mice, the C22:5(n-3) and C22:6(n-3) plasma phospholipid content represented, respectively, no more than $31.6 \pm 3.3$ and $12.0 \pm 1.8 \%(\mathrm{p}<0.02)$ of the corresponding values found in control animals of the same sex. The C22:5(n-3)/ $\mathrm{C} 22: 6(\mathrm{n}-3)$ ratio was $2.63 \pm 0.12$ times higher $(\mathrm{n}=2 ; \mathrm{p}<0.005)$ in (n-3)-depleted mice than in control animals.

Second, the plasma phospholipid content in the long-chain polyunsaturated (n-6) fatty acids C20:4(n-6) and C22:4(n-6) was much higher in the (n-3)-depleted mice than in the control 
Table II. Fatty acid pattern of plasma phospholipid.

\begin{tabular}{|c|c|c|c|c|}
\hline Rats & M-control & F-control & $M-(n-3) D$ & F-(n-3)D \\
\hline $\mathrm{C} 16: 0(\%)$ & 27.7 & 24.2 & 25.1 & 25.1 \\
\hline $\mathrm{C} 16: 1(\mathrm{n}-7)(\%)$ & 0.7 & 0.4 & 0.6 & 0.7 \\
\hline $\mathrm{C} 18: 0(\%)$ & 10.3 & 14.6 & 14.7 & 15.3 \\
\hline C18:1(n-9) (\%) & 6.0 & 4.8 & 7.5 & 8.7 \\
\hline C18:2(n-6) (\%) & 29.5 & 32.4 & 28.9 & 24.8 \\
\hline $\mathrm{C} 18: 3(\mathrm{n}-6)(\%)$ & 0.2 & 0.1 & 0.2 & 0.2 \\
\hline $\mathrm{C} 20: 0(\%)$ & 0.4 & 0.3 & 0.4 & 0.2 \\
\hline C20:1(n-9) (\%) & 0.2 & 0.2 & 0.3 & 0.2 \\
\hline $\mathrm{C} 22: 0(\%)$ & 0.5 & 0.3 & 0.5 & 0.4 \\
\hline $\mathrm{C} 20: 4(\mathrm{n}-6)(\%)$ & 10.7 & 11.9 & 19.6 & 22.0 \\
\hline C22:1(n-9) (\%) & 0.2 & 0.0 & 0.2 & 0.0 \\
\hline $\mathrm{C} 20: 5(\mathrm{n}-3)(\%)$ & 0.9 & 1.0 & 0.0 & 0.0 \\
\hline $\mathrm{C} 24: 0$ & 0.4 & 0.3 & 0.3 & 0.3 \\
\hline $\mathrm{C} 22: 4(\mathrm{n}-6)(\%)$ & 0.0 & 0.0 & 0.4 & 0.4 \\
\hline $\mathrm{C} 22: 5(\mathrm{n}-3)(\%)$ & 0.7 & 0.5 & 0.2 & 0.2 \\
\hline$C 22: 6(n-3)(\%)$ & 11.6 & 8.7 & 0.9 & 1.2 \\
\hline $\mathrm{C} 16: 1(\mathrm{n}-7) / \mathrm{C} 16: 0\left(\mathrm{x} 10^{3}\right)$ & 24.6 & 14.6 & 24.4 & 26.4 \\
\hline C18:1(n-9)/C18:0 & 0.584 & 0.331 & 0.511 & 0.569 \\
\hline C18:0/C16:0 & 0.371 & 0.604 & 0.585 & 0.609 \\
\hline C20:0/C18:0 (x103) & 38.7 & 17.7 & 25.7 & 15.9 \\
\hline $\mathrm{C} 22: 0 / \mathrm{C} 20: 0$ & 1.28 & 1.26 & 1.46 & 1.57 \\
\hline $\mathrm{C} 24: 0 / \mathrm{C} 22: 0$ & 0.735 & 0.912 & 0.612 & 0.564 \\
\hline C20:4(n-6)/C18:2(n-6) & 0.364 & 0.368 & 0.679 & 0.889 \\
\hline $\mathrm{C} 22: 5(\mathrm{n}-3) / \mathrm{C} 22: 6(\mathrm{n}-3)\left(\mathrm{x} 10^{3}\right)$ & 60.5 & 59.2 & 166.8 & 148.9 \\
\hline
\end{tabular}

animals. The weight percentage of C20:4(n-6) averaged $20.8 \pm 1.2 \%$ in the $(n-3)$-depleted mice, as distinct $(\mathrm{p}<0.02)$ from only $11.3 \pm 0.6 \%$ in the control animals. Whilst no C22:4(n-6) could be detected in the plasma phospholipids of control animals, its concentration averaged $4.72 \pm 0.89 \mu \mathrm{g} / \mathrm{ml}$ in the (n-3)-depleted rats, the latter value yielding a relative weight contribution of $4.35 \pm 0.02 \%$ o. Moreover, the C20:4(n-6)/ C18:2(n-6) ratio in plasma phospholipids was increased $(\mathrm{p}<0.03)$ from $36.5 \pm 0.2 \%(\mathrm{n}=2)$ in control mice to $78.3 \pm 10.4 \%$ $(\mathrm{n}=2)$ in $(\mathrm{n}-3)$-depleted mice, suggesting facilitated stepwise conversion of $\mathrm{C} 18: 2(\mathrm{n}-6)$ to $\mathrm{C} 20: 4(\mathrm{n}-6)$.

Third, in the female (n-3)-depleted mice, the C16:1(n-7)/ $\mathrm{C} 16: 0$ and $\mathrm{C} 18: 1(\mathrm{n}-9) / \mathrm{C} 18: 0$ ratios were increased to $176.3 \pm 4.8 \%(n=2 ; p<0.005)$ of the corresponding values found in female control animals. Such was not the case, however, in male mice with an (n-3)-depleted/control mean ratio of $93.0 \pm 5.7 \%(n=2 ; p>0.35)$.

Last, the $\mathrm{C} 18: 0 / \mathrm{C} 16: 0$ and $\mathrm{C} 22: 0 / \mathrm{C} 20: 0$ ratios averaged in the $(n-3)$-depleted mice $122.7 \pm 11.6 \%(n=4)$ of the corresponding control values found in control mice of the same sex, as distinct $(\mathrm{p}<0.01)$ from an $(\mathrm{n}-3)$-depleted/control mean percentage of $74.3 \pm 6.7 \%(n=4)$ for the $C 20: 0 / C 18: 0$ and C24:0/C22:0 ratios.
Liver phospholipids. The total fatty acid content of liver phospholipids was decreased in the (n-3)-depleted mice to $85.2 \pm 1.8 \%(n=2 ; p<0.02)$ of the corresponding values found in control mice of the same sex (Table III).

The fatty acid pattern of liver phospholipids also vastly differed in control and (n-3)-depleted mice. First, the C20:5(n-3), C22:5(n-3) and C22:6(n-3) content of liver phospholipids averaged, respectively, $0.0 \pm 0.0,24.9 \pm 0.1$ and $373.5 \pm 64.2 \mu \mathrm{g} / \mathrm{g}$ wet wt in the (n-3)-depleted rats, as distinct ( $<<0.006$ or less) from $243.3 \pm 17.3,235.2 \pm 5.8$ and $4967.1 \pm 153.0 \mu \mathrm{g} / \mathrm{g}$ in the control animals. The $\mathrm{C} 22: 5(\mathrm{n}-3) / \mathrm{C} 22: 6(\mathrm{n}-3)$ ratio represented in the male and female (n-3)-depleted mice, respectively, 170.3 and $119.6 \%$ of the corresponding value found in control mice of the same sex, suggesting facilitated conversion of C22:6(n-3) to C22:5(n-3) in the (n-3)-depleted animals.

Second, despite the lower total fatty acid content of liver phospholipids in the (n-3)-depleted mice, that of C20:4(n-6) and $\mathrm{C} 22: 4(\mathrm{n}-6)$ averaged, in the same mice, respectively $148.8 \pm 10.0 \%(n=2 ; p<0.03)$ and $296.8 \pm 71.6 \%(n=2 ; p<0.05)$ of the corresponding value recorded in control mice of the same sex. Moreover, both the C20:4(n-6)/C18:2(n-6) and C22:4(n-6)/C20:4(n-6) ratio of liver phospholipids were higher in the (n-3)-depleted mice than control animals, averaging 
Table III. Fatty acid content and pattern of liver phospholipids.

\begin{tabular}{|c|c|c|c|c|}
\hline Rats & M-control & F-control & $M-(n-3) D$ & $F-(n-3) D$ \\
\hline Total content (mg/g) & 26.18 & 25.30 & 21.83 & 22.01 \\
\hline $\mathrm{C} 14: 0(\%)$ & 0.1 & 0.1 & 0.1 & 0.1 \\
\hline $\mathrm{C} 16: 0(\%)$ & 21.3 & 21.5 & 20.5 & 20.0 \\
\hline $\mathrm{C} 16: 1(\mathrm{n}-7)(\%)$ & 0.9 & 0.6 & 1.0 & 1.1 \\
\hline C18:0 (\%) & 11.4 & 14.0 & 14.9 & 15.2 \\
\hline C18:1(n-9) (\%) & 6.1 & 5.8 & 7.4 & 11.0 \\
\hline C18:2(n-6) (\%) & 19.5 & 15.8 & 19.9 & 16.8 \\
\hline $\mathrm{C} 18: 3(\mathrm{n}-6)(\%)$ & 0.2 & 0.3 & 0.4 & 0.2 \\
\hline $\mathrm{C} 20: 0(\%)$ & 0.3 & 0.1 & 0.3 & 0.1 \\
\hline C18:3(n-3) (\%) & 0.3 & 0.2 & 0.0 & 0.0 \\
\hline $\mathrm{C} 20: 1(\mathrm{n}-9)(\%)$ & 0.2 & 0.1 & 0.3 & 0.3 \\
\hline C20:2(n-6) (\%) & 0.3 & 0.2 & 0.4 & 0.3 \\
\hline $\mathrm{C} 22: 0(\%)$ & 0.7 & 0.4 & 0.6 & 0.4 \\
\hline C20:4(n-6) (\%) & 16.4 & 19.4 & 31.2 & 31.2 \\
\hline C20:5(n-3) (\%) & 1.0 & 0.9 & 0.0 & 0.0 \\
\hline $\mathrm{C} 24: 0(\%)$ & 0.6 & 0.4 & 0.5 & 0.4 \\
\hline $\mathrm{C} 22: 4(\mathrm{n}-6)(\%)$ & 0.2 & 0.2 & 0.7 & 0.6 \\
\hline $\mathrm{C} 22: 5(\mathrm{n}-3)(\%)$ & 0.9 & 0.9 & 0.1 & 0.1 \\
\hline C22:6(n-3) (\%) & 19.6 & 19.0 & 1.4 & 2.0 \\
\hline $\mathrm{C} 16: 1(\mathrm{n}-7) / \mathrm{C} 16: 0\left(\mathrm{x} 10^{3}\right)$ & 41.2 & 29.2 & 47.7 & 53.8 \\
\hline C18:1(n-9)/C18:0 & 0.537 & 0.414 & 0.493 & 0.724 \\
\hline C20:4(n-6)/C18:2(n-6) & 0.841 & 1.229 & 1.570 & 1.852 \\
\hline$C 22: 4(n-6) / C 20: 4(n-6)\left(x 10^{3}\right)$ & 9.40 & 12.12 & 22.26 & 20.24 \\
\hline C20:1(n-9)/C18:1(n-9) (x103) & 37.9 & 25.8 & 42.8 & 23.8 \\
\hline$C 22: 5(n-3) / C 22: 6(n-3)\left(x 10^{3}\right)$ & 47.1 & 47.7 & 80.2 & 57.0 \\
\hline
\end{tabular}

$198.9 \pm 34.9 \%(n=4 ; p<0.01)$ of the corresponding values found in control mice of the same gender.

No significant difference of the C20:1(n-9)/C18:1(n-9) ratio was found in the liver phospholipids of control and (n-3)-depleted mice. However, the values recorded in female mice only represented $61.5 \pm 6.3 \%(n=2 ; p<0.05)$ of the corresponding values found in male mice in the same nutritional state (control or (n-3)-depleted mice).

Last, as already observed in plasma phospholipids, the C16:1(n-7)/C16:0 and C18:1(n-9)/C18:0 ratios in liver phospholipids were higher in female (n-3)-depleted mice than in female control rats, with an (n-3)-depleted/control mean ratio of $179.7 \pm 4.6 \%(n=2 ; p<0.005)$, whilst such was not the case in the male mice with a (n-3)-depleted/control mean ratio of $103.1 \pm 12.0 \%(n=2 ; p>0.8)$.

As a matter of fact, there were always highly significant correlation between the weight percentages of a given fatty acid in liver and plasma phospholipids, both expressed relative to the corresponding overall mean value found in the four types of mice. Such was indeed the case for the five saturated fatty acids (C16:0, C18:0, C20:0, C22:0 and C24:0) with a correlation coefficient of $0.854(n=20 ; p<0.001)$, for the three monodesaturated fatty acids [C16:1(n-7), C18:1(n-9) and C20:1(n-9)] with a correlation coefficient of $0.717(n=12$; $\mathrm{p}<0.01$ ), for the long-chain polyunsaturated (n-6) fatty acids [C18:2(n-6), C20:4(n-6) and C22:4(n-6)] with a correlation coefficient of $0.954(n=12 ; p<0.001)$, and for the long-chain polyunsaturated (n-3) fatty acids $[C 20: 5(n-3), C 22: 5(n-3)$ and C22:6(n-3)] with a correlation coefficient of $0.965(n=12$; $\mathrm{p}<0.01)$.

\section{Discussion}

The present results document that second-generation mice depleted in long-chain polyunsaturated (n-3) fatty acids provide a suitable model for extending to these animals the study of the metabolic and functional anomalies resulting from such a depletion.

A number of similarities are indeed observed between the changes in fatty acid composition of plasma and liver lipids in these mice, when compared to those previously identified in second generation (n-3)-depleted rats $(5,6)$.

First, such similarities refer to the severe decrease in the $\mathrm{C} 20: 5(\mathrm{n}-3), \mathrm{C} 22: 5(\mathrm{n}-3)$ and $\mathrm{C} 22: 6(\mathrm{n}-3)$ content of plasma 
and liver lipids. In both plasma and liver phospholipids the C22:5(n-3)/C22:6(n-3) ratio was higher in (n-3)-depleted rats than in control animals. Thus, pooling together all available data, the (n-3)-depleted/control mean value for such a ratio averaged $172.2 \pm 27.5 \%(n=4 ; p<0.01$ versus unity), suggesting facilitated conversion of $\mathrm{C} 22: 6(n-3)$ to $\mathrm{C} 22: 5(\mathrm{n}-3)$ in the (n-3)depleted mice.

Second, the weight percent of long-chain polyunsaturated (n-6) fatty acids underwent opposite changes in the plasma triacylglycerols and phospholipids of (n-3)-depleted rats. In the plasma triacylglycerols, the weight percentage of the two most abundant (n-6) fatty acids [C18:2(n-6) and C18:3(n-6)] was lower in (n-3)-depleted mice than in control animals. On the contrary, in both the plasma and liver phospholipids, the weight percentages of C20:4(n-6) and C22:4(n-6) were higher in (n-3)-depleted mice than in control animals. This coincided with the fact that the C20:4(n-6)/C18:2(n-6) and C22:4(n-6)/C20:4(n-6) ratios in both plasma and liver phospholipids were much higher in the (n-3)-depleted mice than in control animals, suggesting facilitated generation of C20:4(n-6) and $C 22: 4(n-6)$ from their precursors in the former mice.

Third, the weight percentages of several saturated and monodesaturated fatty acids in plasma triacylglycerols were higher in the (n-3)-depleted mice than in control animals. In the plasma and liver phospholipids of female mice, the depletion in (n-3) fatty acids was also accompanied by an apparent increase in $\Delta 9$-desaturase activity (see below). Last, the ratio between several saturated fatty acids $(\mathrm{C} 16: 0, \mathrm{C} 18: 0$, $\mathrm{C} 22: 0$ and C24:0) were also affected in both male and female (n-3)-depleted mice, when compared to control animals of the same sex.

In addition to these findings, the present results also extend previous observations on two other sets of data. First, they reveal that, like in control and (n-3)-depleted rats, highly significant correlations are found between the weight percentages of fatty acids in liver versus plasma phospholipids of control and (n-3)-depleted mice. Such a finding indicates that the measurement of the fatty acid profile in plasma lipids represents a reliable information to assess the severity of the depletion in long-chain polyunsaturated (n-3) fatty acids and its consequences, in terms of changes in both the weight percentage of other fatty acids, e.g. long-chain polyunsaturated (n-6) fatty acids, and the ratio between selected fatty acids, e.g. those ratios [C16:1(n-7)/C16:0 and C18:1(n-9)/C18:0] relevant to the activity of $\Delta 9$-desaturase.

Second, the present results document a number of gender differences on such variables as the C18:0, C18:1(n-9) and C20:0 weight percentages in plasma triacylglycerols and the C20:0, C22:0 and C24:0 weight percentages in plasma phospholipids. Once again, in these respects, the present results were comparable to those recently recorded in control and (n-3)-depleted rats (unpublished data). Another striking gender difference consisted in the fact that the changes in the $\mathrm{C} 16: 1(\mathrm{n}-7) / \mathrm{C} 16: 0$ and $\mathrm{C} 18: 1(\mathrm{n}-9) / \mathrm{C} 18: 0$ ratios in both plasma and liver lipids, as attributable to the depletion in (n-3) fatty acids, was quite obvious in female mice, but not so in male mice. Indeed, pooling all available data, the (n-3)depleted/control mean value for these two ratios averaged $167.8 \pm 12.8 \%$ ( $n=6 ; p<0.001$ versus unity) in female mice, as distinct $(\mathrm{p}<0.001)$ from $98.0 \pm 4.4 \%(\mathrm{n}=6 ; \mathrm{p}>0.6$ versus unity) in male mice. Last, in the control animals, the C20:5(n-3), C22:5(n-3) and C22:6(n-3) weight percentages in plasma triacylglycerols were much lower in female mice than in male animals.

In conclusion, the animal model presented in this study indeed appears suitable for further investigations on the metabolic, hormonal and functional consequences of a depletion in long-chain polyunsaturated (n-3) fatty acids, as presently often prevailing in Western populations.

\section{Acknowledgements}

This study was supported by a grant from the Belgian Foundation for Scientific Medical Research (3.4574.07). We are grateful to A. Chwalik and A. Dufour for technical assistance and to C. Demesmaeker and P. Surardt for secretarial help.

\section{References}

1. Oguzhan B, Sancho V, Acitores A, Villanueva-Penacarrillo ML, Portois L, Chardigny J-M, Sener A, Carpentier YA and Malaisse WJ: Alteration of adipocyte metabolism in $\omega 3$ fatty acid-depleted rats. Horm Metab Res 38: 789-798, 2006.

2. Oguzhan B, Zhang Y, Louchami K, Courtois P, Portois L, Chardigny J-M, Malaisse WJ, Carpentier YA and Sener A: Pancreatic islet function in $\omega 3$ fatty acid-depleted rats. Glucose metabolism and nutrient-stimulated insulin release. Endocrine 29: 467-476, 2006.

3. Armitage JA, Pearce AD, Sinclair AJ, Vingrys AJ, Weisinger RS and Weisinger HS: Increased blood pressure later in life may be associated with perinatal n-3 fatty acid deficiency. Lipids 38 : 459-464, 2003.

4. Peltier S, Malaisse WJ, Portois L, Demaison L, Novel-Chate V, Chardigny J-M, Sebedio J-L, Carpentier YA and Leverve XM: Acute in vivo administration of a fish oil-containing emulsion improves post-ischemic cardiac function in $\omega 3$-depleted rats. Int J Mol Med 18: 741-749, 2006.

5. Carpentier YA, Peltier S, Portois L, Chardigny J-M, Sebedio J-L, Leverve $\mathrm{X}$ and Malaisse WJ: Accelerated clearance of plasma triglycerides and free fatty acids in $\omega 3$-depleted rats. Horm Metab Res 39: 295-305, 2007.

6. Louchami K, Zhang Y, Oguzhan B, Delporte C, Portois L, Carpentier YA, Genten F, Danguy A, Malaisse WJ and Sener A: Rapid changes in liver lipid composition and pancreatic $\mathrm{K}^{+}$ handling and secretory behaviour provoked by the intravenous administration of a medium-chain triglyceride:fish oil emulsion to long-chain polyunsaturated $\omega 3$ fatty acid-depleted rats. Int J Mol Med 18: 1047-1055, 2006. 